\title{
A hotspot of non-native marine fishes: evidence for the aquarium trade as an invasion pathway
}

\author{
Brice X. Semmens ${ }^{1, *}$, Eric R. Buhle ${ }^{1}$, Anne K. Salomon ${ }^{1}$, Christy V. Pattengill-Semmens ${ }^{2}$
}

${ }^{1}$ University of Washington, 24 Kincaid Hall, Department of Biology, Box 351800, Seattle, Washington 98195-1800, USA

${ }^{2}$ Reef Environmental Education Foundation (REEF), PO Box 246, Key Largo, Florida 33037, USA

\begin{abstract}
Invasions of non-native species in marine ecosystems can be ecologically damaging and economically costly. Identifying 'hot-spots' of non-native species and their sources of introduction is necessary to maximize the effectiveness of invasion quarantine programs. We use a large spatially explicit marine fish database to show that there are a surprising number of non-native fishes on the reefs of southeast Florida, USA. Two likely sources explain the occurrence of non-native marine fishes in this region: introductions through ballast-water exchange, and introductions from aquaria. Data on international shipping patterns and marine fish imports were used to evaluate the culpability of these 2 vectors. Our results suggest that the introductions are the result of aquarium releases. Prevention of further releases and invasions will require education, outreach, and enforcement efforts directed at marine aquarists and the aquarium industry.
\end{abstract}

KEY WORDS: Non-indigenous species · Aquarium trade $\cdot$ Reef fish · Ballast water · Marine conservation · Reef Environmental Education Foundation · Invasion control

Resale or republication not permitted without written consent of the publisher

\section{INTRODUCTION}

Biological invasions are increasingly recognized as a primary threat to global biodiversity (Wilcove et al. 1998, Bax et al. 2001, D'Antonio et al. 2001). In aquatic systems, ballast-water transfer by oceangoing vessels has been identified as a leading invasion pathway (Carlton \& Geller 1993, Wonham et al. 2000, 2001). Other frequently cited vectors for marine species introductions include the intentional or accidental transport of species in shipments of fisheries products (Elton 1958, Carlton 1989) and the deliberate release of nonindigenous species to create or enhance commercial fisheries (Randall 1987). Although the intentional release or escape of fishes from private aquaria and ornamental fish farms has led to successful freshwater fish invasions (Courtenay \& Robins 1973, Courtenay \& Stauffer 1990, Shafland 1996), the role of the aquarium trade in marine invasions has received little attention.

Recently, Whitfield et al. (2002) documented the presence and likely establishment of the Indo-Pacific lionfish Pterois volitans in the western Atlantic. They postulated that the source of the introduction was the marine aquarium trade. This is not the first time that aquarium releases have been identified as the probable source of marine fish introductions (Randall 1987), but to our knowledge it is the first time aquarium releases have been identified as the likely source of a successfully established non-native marine fish.

While some of the most notorious invaders are freshwater fishes (Zaret \& Paine 1973, Goldschmidt et al. 1993), successful invasions of tropical marine fish species are either rare or rarely reported. This may be in part due to the fact that few biologists are underwater looking. Of the 1145 successful fish introductions documented in Froese \& Pauly (2002), only 241 are marine. Of these, 94 occurred in the tropics. Given the spatial extent and taxonomic richness of tropical marine systems, the plethora of vectors, and the degree of international trade and transport among coastal regions, it is unclear why there have not been more documented successful marine fish invasions.

Generally, invasion success may be influenced by characteristics of the invader, such as intrinsic growth rates, trophic status, and reproductive life history (Byers \& Goldwasser 2001, Fausch et al. 2001), as 
well as attributes of the recipient community, such as degraded habitat, productivity, and species interactions (Simberloff 1986, Lodge 1993, Moyle \& Light 1996, Reusch 1998, Levine \& D'Antonio 1999). However, experimental and comparative evidence indicate that all else being equal, the probability of success increases with increasing propagule pressure, i.e. the frequency of introduction attempts and the number of individuals introduced (Levine 2000, Kolar \& Lodge 2001).

There is ample evidence that given enough propagule pressure, fishes can successfully invade tropical marine systems (Planes \& Lecaillon 1998). Probably the best-known case of the successful establishment of non-indigenous fish species has occurred in the Hawaiian Islands (Randall 1987). Between 1955 and 1961 the Hawaiian Islands Division of Fish and Game attempted to introduce 11 species of marine fishes from the families Serranidae (grouper) and Lutjanidae (snapper) for the purposes of enhancing near-shore fisheries. Of those, Cephalophis argus (peacock grouper), Lutjanus fulvus (blackfin snapper), and Lutjanus kasmira (bluestriped snapper) became established. Additionally, 2 silverside species, Herklotsichthys quadrimaculatus (goldspot herring) and Sardinella marquesensis (Marquesan sardine) were unintentionally introduced when dumped in large numbers from ship holds following research and exploratory fishing cruises off the Hawaiian archipelago (Randall 1987). There is also anecdotal information that 13 species from the tropical western Atlantic were intentionally introduced to Bermuda for commercial and game fishing in the 1920s (Walford \& Wicklund 1973). Of those, Pomacanthus ciliaris (queen angelfish), Pomacanthus arcuatus (grey angelfish), and Lutjanus analis (mutton snapper) have become es-

Table 1. Non-native fish species documented by REEF volunteers and the number of locations at which each has been sighted

\begin{tabular}{|llc|}
\hline Common name & \multicolumn{1}{c|}{ Scientific name } & Locations \\
\hline Lionfish & Pterois volitans (Linnaeus, 1758) & 5 \\
Panther grouper & Chromileptes altivelis (Valenciennes, 1828) & 1 \\
Racoon butterflyfish & Chaetodon lunula (Lacepède, 1802) & 1 \\
Orbicular batfish & Platax orbicularis (Forsskål, 1775) & 3 \\
Blue ringed angelfish & Pomacanthus annularis (Bloch, 1787) & 1 \\
Arabian angelfish & Pomacanthus asfur (Forsskål, 1775) & 2 \\
Emperor angelfish & Pomacanthus imperator (Bloch, 1787) & 6 \\
Yellowbar angelfish & Pomacanthus maculosus (Forsskål, 1775) & 3 \\
Semicircle angelfish & Pomacanthus semicirculatus (Cuvier, 1831) & 3 \\
Moorish idol & Zanclus cornutus (Linnaeus, 1758) & 1 \\
Orangespine unicornfish & Naso lituratus (Forster, 1801) & 1 \\
Sohal surgeonfish & Acanthurus sohal (Forsskål, 1775) & 1 \\
Sailfin tang & Zebrasoma desjardinii (Bennett, 1836) & 1 \\
Yellow tang & Zebrasoma flavescens (Bennett, 1828) & 3 \\
Sailfin tang & Zebrasoma veliferum (Bloch, 1795) & $6^{\text {a }}$ \\
Yellowtail sailfin tang & Zebrasoma xanthurum (Blyth, 1852) & 2 \\
aThe species of 1 sailfin tang sighting is unknown (veliferum vs desjardinii) & \\
& &
\end{tabular}

tablished (Walford \& Wicklund 1973, REEF 2002). In both Hawaii and Bermuda, when significant propagule pressure was applied through intentional or unintentional introductions, exotic fishes have established self-sustaining populations.

This paper synthesizes recent reports of non-native marine fish species observed off the East Coast of the US. The data presented are a product of the Reef Environmental Education Foundation (REEF), a marine citizen science organization. Our intent is to highlight evidence of significant non-native propagule pressure in the tropical waters off the southeast coast of Florida, and to evaluate the probability that either ballastwater or aquarium releases are the source of these marine fish introductions.

\section{METHODS}

Data sources. Non-native tropical marine fish sightings (Table 1) were documented primarily by sportdivers affiliated with REEF. In most instances, photographic or videographic validation of the sightings was collected and provided to REEF, and multiple individuals have corroborated sightings. When sportdivers reported sightings to REEF they either provided geographic coordinates or gave the name of the dive site where the sighting occurred.

The REEF Fish Survey Project is an ongoing volunteer marine fish monitoring effort that has maintained a publicly accessible database of fish sightings and relative abundance information since 1993. In the tropical western Atlantic, REEF volunteer divers have conducted over 49000 REEF surveys using the Roving Diver Technique (RDT; Schmitt \& Sullivan 1996), including over 16000 surveys off the coast of Florida. During RDT surveys divers swim freely throughout the dive site for 30 to $60 \mathrm{~min}$ and classify the relative abundance of every observed species into 4 categories: single (1); few (2 to 10$)$; many (11 to 100$)$; and abundant $(>100)$. The species data are then transferred to a scansheet and optically scanned into a web-accessible database (http://www.reef.org). In February 2002, REEF added a non-native species reporting form so divers could report sightings without having to complete an RDT survey. Our analysis is based on RDT surveys and additional non-native sightings data collected from 1993 to 2002. All REEF data were plotted to develop maps of non-native sightings and surveyor effort. 
Data from the Global Marine Aquarium Database (GMAD) on US tropical marine fish imports were used to evaluate the likelihood that the sighted non-native species derived from the aquarium trade (GMAD 2002). GMAD provides country- or continent-level import and export data on marine aquarium wholesale companies. The database has been maintained since 2000 as a partnership by the United Nations Environment Program's World Conservation Monitoring Center and the Marine Aquarium Council. Wholesaler participation is voluntary; the industry has no formal monitoring or reporting framework. Despite its limitations, GMAD provides the best available information on global marine aquarium trade practices. We searched the database for marine aquarium fish imports into the US and extracted the total number of individuals of each species reported during 1999-2001. We only used data from these years because the reporting from this time period was the most complete.

The National Ballast Information Clearinghouse (NBIC) Database summarizes information on ballast water management practices reported by ships entering US waters from outside the Exclusive Economic Zone (NBIC 2002). Each record of a ship visit to a US port includes the ship's class, previous port of call (including geographic coordinates), and amount of ballast water discharged. Ship operators are not required to indicate where discharged ballast was acquired, or the location of prior ballast exchanges. In our analysis we only used NBIC data between July 1999 and October 2001 because according to the NBIC website, data from this time period was the most comprehensive (NBIC 2002). Records of ships visiting Florida were grouped by marine geographic regions (Froese \& Pauly 2002) based on previous ports of call. Only ships with previous ports of call in tropical or subtropical marine waters (between $40^{\circ} \mathrm{N}$ and $40^{\circ} \mathrm{S}$ ) were included. All ships with previous ports of call in the tropical western Atlantic were excluded.

Statistical analysis. If the aquarium trade is the source of the non-native marine fishes, then species imported in relatively large quantities are most likely to be observed in the wild. We performed a randomization procedure to test the null hypothesis that the sighted species represent a random sample from all aquarium species imported into the USA. Of the 16 sighted non-native species, 2 species, Zebrasoma veliferum and $Z$. desjardinii, were not distinguished in the import records and were treated as a single taxon for this analysis. We randomly drew samples of 15 species without replacement from the list of all 790 imported species and calculated the median imported quantity for each sample. This was repeated 50000 times to generate a distribution of import abundances for the random samples. We compared this distribution to the median quantity imported for the sighted taxa to calculate a 1-tailed p-value.

If the non-native fishes arrived in ballast water, their native ranges should coincide with areas where shipping traffic originated. However, because fish diversity differs across ocean regions, multiplying regional species richness by the number of shipping voyages may yield a more appropriate index of the opportunity for species introductions from a region. We used each of these indices, shipping traffic and the product of shipping traffic and regional species richness, to calculate the expected number of introduced species from each region, given a total of 16 species. We compared these expected distributions to the observed regional distribution of sighted species using a $\chi^{2}$-test. Because some sighted species are native to more than one ocean region, we performed the test using all possible assignments of species to a unique region of origin.

\section{RESULTS}

Since 1999, divers have reported 16 non-native marine fish species from 32 locales in the western Atlantic through the REEF Fish Survey Project and the online reporting form (Fig. 1). Of the 40 species-by-site reports, 32 have been confirmed by multiple independent sightings or photographic documentation. Ten of the 16 non-native species have been seen at more than 1 location, although only Platax orbicularis (orbicular batfish) and Pterois volitans (Indo-Pacific lionfish) were seen in schools of 2 or more individuals. Only $P$. volitans was reported from a western Atlantic location (Bermuda) outside US waters. All but 8 of these sightings were from a localized area along Palm Beach and Broward Counties, Florida, while only $30 \%$ of the monitoring program surveys were from Florida (REEF 2002). Since all individual fishes were not uniquely identified, it is possible that some individuals were recorded at more than one location; however, we feel this is unlikely given the site fidelity and small home ranges of most reef fish (Kramer \& Chapman 1999). Several of the non-native species have been reported from the same sites over multiple years. For instance, the same individuals of $P$. orbicularis have been resighted on Molasses Reef, Key Largo, Florida, more than 50 times over the last $3 \mathrm{yr}$.

All of the observed non-native species have been imported in the marine aquarium trade (with the possible exception of Zebrasoma desjardinii, which was not distinguished in trade data from the morphologically similar Z. veliferum). Also, sighted species were imported in far larger quantities than would be expected if they were drawn randomly from the list of aquarium imports ( $p<0.0001$, Fig. 2). We considered the pos- 

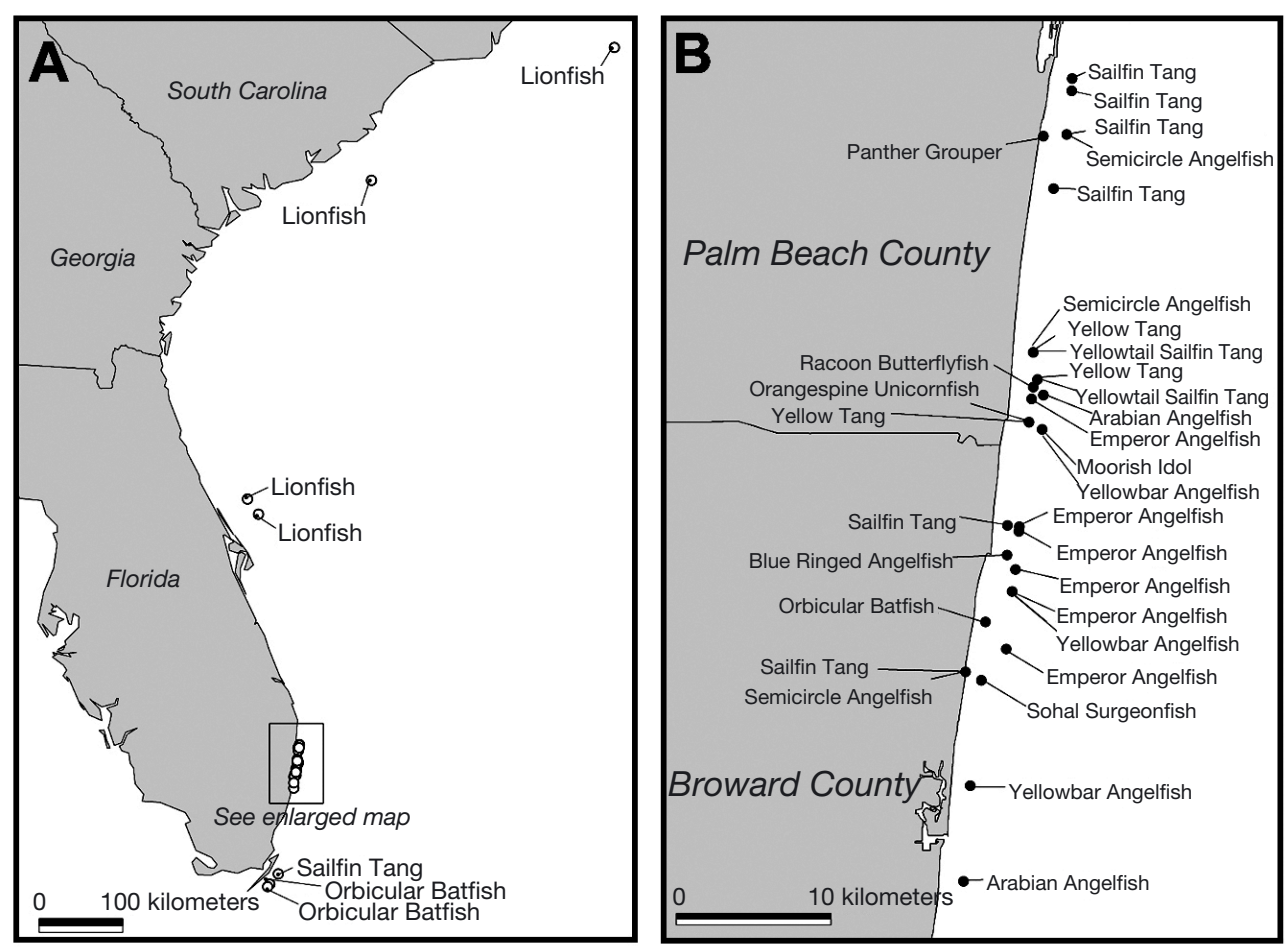

Fig. 1. Locations of non-native marine fish sightings along the southeastern US (A) and along Palm Beach and Broward Counties, Florida (B). The REEF database also includes sightings of Pterois volitans from Bermuda that are not shown here. Sightings are reported by sport-divers through the Reef Environmental Education Foundation (REEF) Fish Survey Project (REEF 2002) and through an on-line reporting form (http://www. reef.org/exotic)

sibility that this result was driven by the sighting of yellow tang Zebrasoma flavescens, which is imported in very large numbers. When we excluded yellow tang from the sightings list and repeated the randomization analysis with the highest-ranked species discarded from each sample, the results were unchanged. This strongly suggests that, for ornamental marine fishes, a link exists between the magnitude of importation and the probability of being sighted along the eastern US coast.

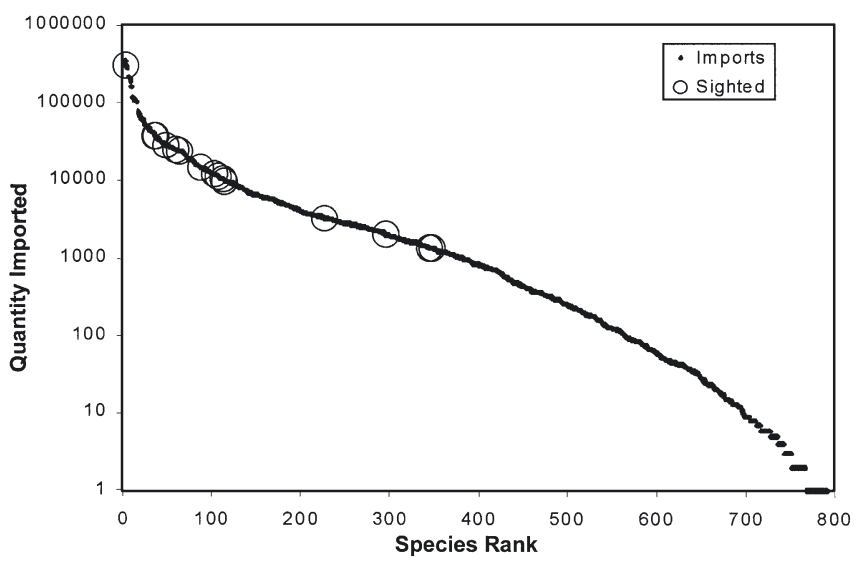

Fig. 2. All marine fish species imported to the US in the aquarium trade (GMAD 2002) are rank-ordered by imported quantity from left (highest) to right (lowest). Points representing non-native species seen in diver surveys are circled. Note the log scale of the $y$-axis
The native range distribution of sighted species deviated strongly from the expected distribution based on either shipping traffic or the product of ship visits and regional species richness $\left(\chi^{2} \geq 552.0, \mathrm{df}=9, \mathrm{p}<10^{-15}\right.$, for all possible assignments of species to regions). The sighted species are native to just 2 ocean regions, the tropical western Pacific Ocean and the northwest Indian Ocean and Red Sea, which together contribute $9.4 \%$ of all shipping visits to Florida (Fig. 3).

\section{DISCUSSION}

Marine invasions have the potential to fundamentally shift the ecology of a region by modifying ecosystem processes, community composition, and food-web dynamics (Verlaque \& Fritayre 1994, Shiganova 1998, Grosholz et al. 2000). Such ecological shifts can damage regional economies (Pimentel et al. 1999). In the Black Sea and San Francisco Bay, for example, the costs of invasion impacts and control efforts have been staggering (Travis 1993, Cohen \& Carlton 1998).

What has been the ecological impact of marine fish introductions? The largest set of intentional marine fish introductions were carried out in the temperate coastal and inland seas of Russia (Baltz 1991). Sixteen species became established, with ecologically and economically devastating results including harm to valuable fisheries, parasite introductions, and the endangerment and extinction of native species (Baltz 1991). 


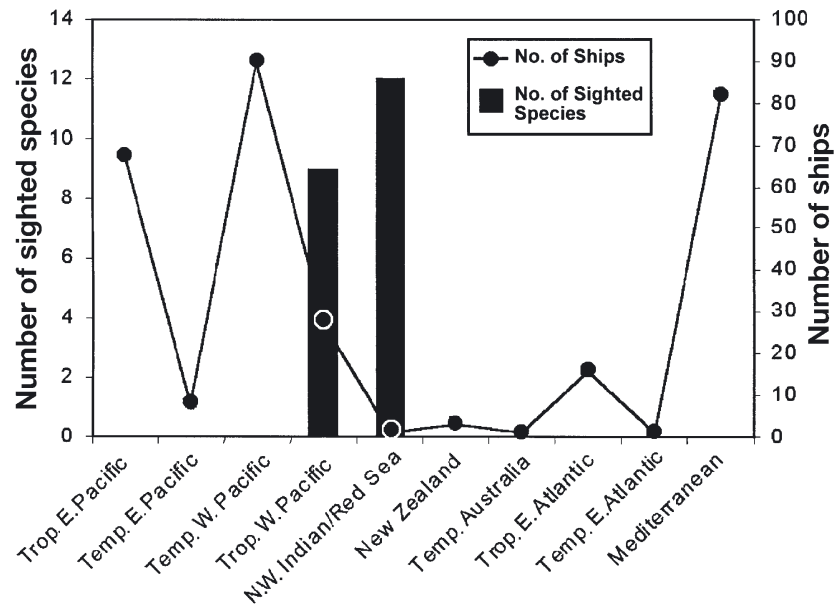

Fig. 3. Numbers of ships arriving in Florida between 1999 and 2001 from each marine geographic region (Froese \& Pauly 2002) and numbers of non-native species sighted off Florida with native ranges in each region. Note that, because some species are found in more than 1 region, the sum of thebar plots is greater than 16 (the number of non-native species sighted)

To date, no reports of established non-native tropical marine fishes have documented significant changes in community composition, economic impacts, or superabundance of the invader (Randall 1987, Froese \& Pauly 2002). This may simply reflect limited opportunity, given the small number of successful tropical marine fish introductions and the typically low proportion of invaders that attain pest status (Williamson \& Fitter 1996). Alternatively, it may be due to the lack of quantitative studies that examine the effect of marine invasive fishes on native communities. Assessing the ecological impact of non-native marine fishes rather than simply documenting their presence, abundance, and distribution must be a research priority in future investigations. With sufficient propagule pressure, it is likely that continued introductions will result in invasions with significant negative ecological and economic impacts. Furthermore, the changes in habitat characteristics and disturbance regimes that Caribbean reefs are currently undergoing (GCRMN 2002) may ultimately facilitate such invasions as reef communities become increasingly disturbed (Hobbs 1989, Moyle \& Light 1996).

The sightings reported here, combined with previous reports (Courtenay 1995), indicate that propagule pressure of non-native tropical marine fish off southeastern Florida is both substantial and chronic. Moreover, recent sightings of juvenile and adult Pterois volitans along the eastern US and in the western Atlantic suggest that at least one of these species has established a self-sustaining population (Whitfield et al. 2002). It remains to be seen what impacts $P$. volitans will have on the regional ecology and economy.
Ballast-water transport and aquarium releases are the 2 most probable pathways of tropical marine fish introductions in the Caribbean (Whitfield et al. 2002). The higher abundance of non-native fishes near areas of high human population density off the southeast coast of Florida (Fig. 1) is consistent with both pathways. We used the best available information from both the aquarium and shipping industries to evaluate the culpability of these 2 pathways. Our results indicate that the non-native species seen are consistent with the hypothesis that the individuals have escaped or have been released from aquaria. In the near term, this should be sufficient evidence to reallocate management and prevention resources to address the problem of marine fish aquarium releases.

Intentional and unintentional aquarium releases have been identified as a leading cause of freshwater fish invasions (Courtenay \& Robins 1973, Courtenay \& Stauffer 1990) and, more recently, as the vector responsible for the invasion of the marine alga Caulerpa taxifolia in the Mediterranean (Verlaque \& Fritayre 1994, Jousson et al. 1998). In Florida, as in nearly all states, releasing fishes from captivity is illegal (King \& Schrock 1985), but enforcement is difficult and aquarists and the aquarium industry are not well informed about the existence of such laws. Courtenay \& Robins (1973) suggested that the aquarium industry, in conjunction with natural resource agencies, develop a program to educate dealers and aquarists about the legality and environmental impacts of exotic-species introductions, but little progress has been made to date (W. Courtenay pers. comm.). Public education is especially critical in areas such as the southeastern US and Hawaii, which have regional climates and habitats suitable for the tropical marine fish species common in the aquarium trade, and hence are at relatively high risk of successful introductions.

The presence of 16 non-native marine fish species off the southeastern coast of the US should spur researchers and managers to take several actions. The density and reproductive status of each exotic species must be determined. If the problem is currently restricted to a few isolated adults, it may be possible to remove all or most of the individuals and prevent the establishment of a viable population. Rapid response is crucial in the case of invaders with pelagic larval dispersal because even a few successful reproductive events will likely make eradication impossible (Simberloff 2003). If eradication is already infeasible, efforts should be made to evaluate the rate and direction of spread of the invasions and their ecological impacts. The results presented in this paper identify a significant threat to coastal ecosystems and present a rare opportunity for proactive management of marine-species introductions, provided managers and scientists act quickly. 
Acknowledgements. We thank D. Boersma, W. Courtenay, G. Helfman, S. Naeem, J. Ruesink, D. Schindler, P. Whitfield, and $\mathrm{M}$. Wonham for insightful comments and formative ideas regarding this paper. Thanks also to 3 anonymous reviewers for their valuable comments. This research would not have been possible without the dedicated efforts of REEF volunteers.

\section{LITERATURE CITED}

Baltz DM (1991) Introduced fishes in marine systems and inland seas. Biol Conserv 56:151-177

Bax N, Carlton JT, Mathews-Amos A, Haedrich RL, Hogwarth FG, Purcell JE, Rieser A, Gray A (2001) The control of biological invasions in the world's oceans. Conserv Biol 15:1234-1246

Byers JE, Goldwasser L (2001) Exposing the mechanism and timing of impact of nonindigenous species on native species. Ecology 82:1330-1343

Carlton JT (1989) Man's role in changing the face of the ocean: biological invasions and implications for conservation of near-shore environments. Conserv Biol 3:265-273

Carlton JT, Geller JB (1993) Ecological roulette: the global transport of nonindigenous marine organisms. Science 261:78-82

Cohen AN, Carlton JT (1998) Accelerating invasion rate in a highly invaded estuary. Science 279:555-558

Courtenay WR (1995) Marine fish introductions in southeastern Florida. AFS Introduced Fish Sect Newsl 1995:2-3

Courtenay WR, Robins CR (1973) Exotic aquatic organisms in Florida with emphasis on fishes: a review and recommendations. Trans AFS 102:1-12

Courtenay WR, Stauffer JR (1990) The introduced fish problem and the aquarium fish industry. J World Aquacult Soc 21:145-159

D'Antonio C, Meyerson LA, Denslkow J (2001) Exotic species and conservation. In: Soulé ME, Orians GH (eds) Conservation biology; research priorities for the next decade. Island Press, Washington, DC, p 59-80

Elton CS (1958) The ecology of invasions by animals and plants. Methuen, London

Fausch KD, Taniguchi Y, Nakano S, Grossman GD, Townsend CR (2001) Flood disturbance regimes influence rainbow trout invasion success among five Holarctic regions. Ecol Appl 11:1438-1455

Froese R, Pauly D (2002) FishBase. Available at http:// www.fishbase.org (accessed 15 October 2002)

GCRMN (2002) Status of coral reefs of the world: 2002. Australia Institute of Marine Science, Townsville

GMAD (2002) The global marine aquarium database. Available at http://www.unep-wcmc.org/marine/GMAD/ (accessed 15 October 2002)

Goldschmidt T, Witte F, Wanink J (1993) Cascading effects of the introduced Nile perch on the detritivorous/phytoplanktivorous species in the sublittoral areas of Lake Victoria. Conserv Biol 7:686-700

Grosholz ED, Ruiz GM, Dean CA, Shirley KA, Maron JL, Connors PG (2000) The impacts of a nonindigenous marine predator in a California bay. Ecology 81:1206-1224

Hobbs RJ (1989) The nature and effects of disturbance relative to invasions. In: Drake JA, Mooney HA, Di Castri F, Groves RH, Kruger M, Rejmanek M, Williamson M (eds) Biological invasions: a global perspective. Scope 37. John Wiley \& Sons, New York, p 389-405

Jousson O, Pawlowski J, Zainetti L, Meinesz A, Boudouresques CF (1998) Molecular evidence for the aquarium origin of the green alga Caulerpa taxifolia introduced to the Mediterranean Sea. Mar Ecol Prog Ser 172:275-280

King ST, Schrock RS (1985) Controlled wildlife, Vol 3: state regulations. Museum of Natural History, University of Kansas, Lawrence, KA

Editorial responsibility: Otto Kinne (Editor), Oldendorf/Luhe, Germany
Kolar CS, Lodge DM (2001) Progress in invasion biology: predicting invaders. Trends Ecol Evol 16:199-204

Kramer DL, Chapman MR (1999) Implications of fish home range size and relocation for marine function. Environ Biol Fishes 55:65-79

Levine JM (2000) Species diversity and biological invasions: relating local process to community pattern. Science 288: 852-854

Levine JM, D'Antonio CM (1999) Elton revisited: a review of evidence linking diversity and invasibility. Oikos 87:15-26

Lodge DM (1993) Biological invasions: lessons for ecology. Trends Ecol Evol 8:133-137

Moyle PB, Light T (1996) Fish invasions in California: do abiotic factors determine success? Ecology 77:1670-1675

NBIC (2002) National ballast information clearinghouse database. Available at http://invasions.si.edu/NBIC/nbic database.htm (accessed 15 October 2002)

Pimentel D, Lach L, Zuniga R, Morrison D (1999) Environmental and economic costs associated with non-indigenous species in the United States. College of Agriculture and Life Sciences, Cornell University, Ithaca, NY

Planes S, Lecaillon G (1998) Consequence of the founder effect in the genetic structure of introduced island coral reef fish populations. Biol J Linn Soc 63:537-552

Randall JE (1987) Introductions of marine fishes to the Hawaiian Islands. Bull Mar Sci 41:490-502

REEF (2002) Reef Environmental Education Foundation. Available at http://www.reef.org (accessed 15 October 2002)

Reusch TBH (1998) Native predators contribute to invasion resistance to the non-indigenous bivalve Musculista senhousia in southern California, USA. Mar Ecol Prog Ser 170:159-168

Schmitt EF, Sullivan KM (1996) Analysis of a volunteer method for collecting fish presence and abundance data in the Florida Keys. Bull Mar Sci 59:404-416

Shafland PL (1996) Exotic fishes of Florida - 1994. Rev Fish Sci $4: 101-122$

Shiganova TA (1998) Invasion of the Black Sea by the ctenophore Mnemiopsis leidyi and recent changes in pelagic community structure. Fish Ocean 7:305-310

Simberloff D (2003) How much information on population biology is needed to manage introduced species? Conserv Biol $17: 83-92$

Travis J (1993) Invader threatens Black, Azov Seas. Science 263:1366-1367

Verlaque M, Fritayre P (1994) Mediterranean algal communities are changing in face of the invasive alga Caulerpa taxifolia. Oceanol Acta 17:659-672

Walford L, Wicklund R (1973) Contributions to a world-wide inventory of exotic marine and anadromous organisms. FAO Fish Tech Paper No 121, FAO, Rome

Whitfield P, Gardner T, Vives SP, Gilligan MR, Courtenay WR, Carleton R, Hare JA (2002) Biological invasions of the IndoPacific lionfish (Pterois volitans) along the Atlantic coast North America. Mar Ecol Prog Ser 235:289-297

Wilcove DS, Rothstein D, Dubow A, Phillips E, Losos E (1998) Quantifying threats to imperiled species in the United States. BioScience 48:607-615

Williamson M, Fitter A (1996) The varying success of invaders. Ecology 77:1661-1666

Wonham MJ, Carlton JT, Ruiz GM, Smith LD (2000) Fish and ships, relating dispersal frequency to success in biological invasions. Mar Biol 136:1111-1121

Wonham MJ, Walton WC, Ruiz GM, Frese AM, Galil BS (2001) Going to the source: role of the invasion pathway in determining potential invaders. Mar Ecol Prog Ser 215:1-12

Zaret T, Paine RT (1973) Species introduction in a tropical lake. Science 182:449-455

Submitted: May 30, 2003; Accepted: October 25, 2003

Proofs received from author(s): January 20, 2004 